\title{
Study of the effect of liquid humic preparations from vermicompost on the germination of soybean seeds of the "Zhansaya" variety
}

Boguspayev K.K., Titov I.N., Faleyev D.G., Azimova E.D., Akilbekova A., Nusupov A.A. al-Farabi Kazakh National University, Almaty, Kazakhstan, kboguspayev@yandex.ru

Keywords: vermicompost, alkaline extraction, soybean seeds, germination

doi: 10.36291/HIT.2019.boguspayev.058

The technology for producing humic biological products from vermicomposts (biohumus) by alkaline treatment in the liquid phase allows one to obtain concentrated preparations containing almost all components of vermicomposts, including humic acids in high concentrations. In the experiments, for the production of liquid humic products used vermicompost obtained in "comperemedia" piles of cattle manure, with compost worms Eisenia fetida. Vermicompost (humidity 60-70\%) was loaded in the vessel was added 0.1 $\mathrm{M}$ solution of potassium pyrophosphate in $0.1 \mathrm{~N}$. the solution of $\mathrm{KOH}$. Alkaline extraction was performed with constant stirring of the mixture at $80^{\circ} \mathrm{C}$ for $30 \mathrm{~min}$. The resulting mixture was sedimented for 30-60 minutes; the supernatant (alkaline extract) was poured into the storage tank. The alkaline extract was cooled to room temperature and, to obtain the finished product, neutralized with a solution of nitric acid $\mathrm{HNO}_{3}$ to a $\mathrm{pH}$ of 7.0-8.0 [1]. Sterile "Zhansaya" soybean seeds were placed in Petri dishes with a diluted preparation $(1: 100)$ and germinated at room temperature in a germination chamber. Distilled water was used as a control. The duration of the experiment is 7-8 days. The experiment was carried out in three agility.

In fig. 1 presents the results of experiments on the germination of soybean seeds of the variety "Zhansaya" using a liquid humic preparation from vermicompost at a dilution of 1: 100
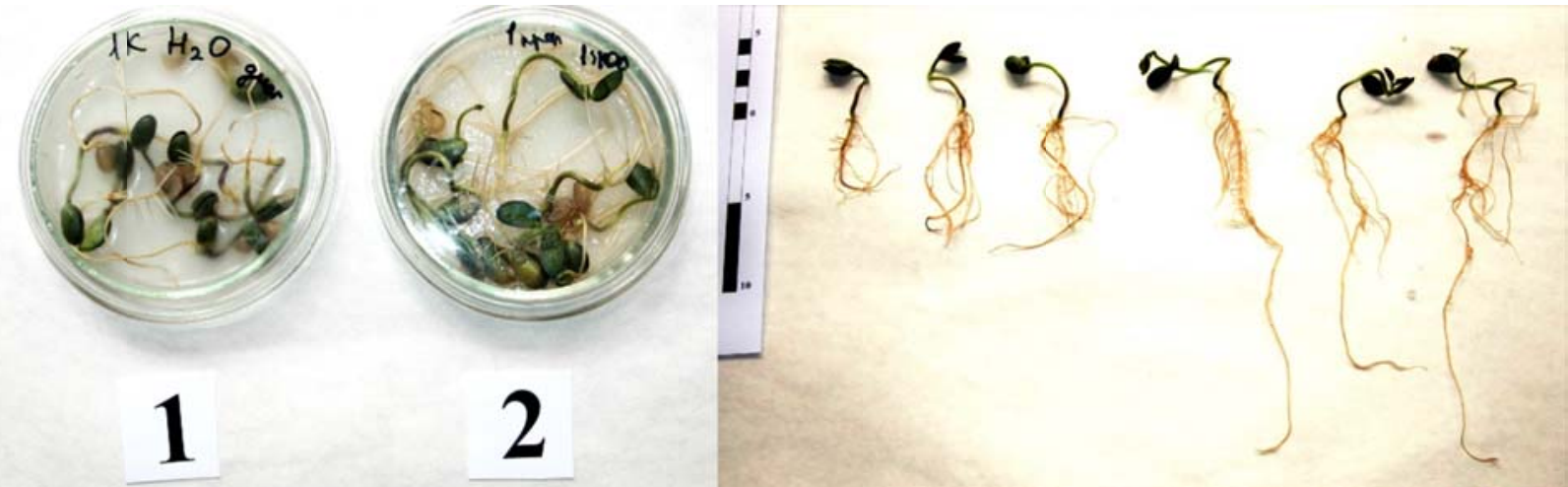

Figure 1. Zhansaya soybean seedlings treated with a liquid humic preparation in a 1: 100 dilution. Left - control, without treatment (distilled water).

Morphometric indicators were used to evaluate the effect of the drug: the length of the main root $(\mathrm{mm})$, the number of lateral roots of the main root (pcs). As a result, it was found that the average length of the main root in the experiment was $195 \mathrm{~mm}$, in the control $-130 \mathrm{~mm}$.), The number of lateral roots of the main root in the experiment was 19 pcs., In control 7 , which clearly indicates the positive effect of liquid humic preparations on the germination of soybean seeds.

References

1. Titov I.N. // In: Materials of the IX International Scientific and Practical Conference daRostim 2013. 